\title{
EEN NIEUWE BIJDRAGE TOT DE KENNIS VAN HET SHAMANISME BIJ DE PASĔMAHERS. ${ }^{1}$ )
}

DOOR

W. HOVEN.

In de berichten van den St. Claverbond van het jaar 1893 komt op blz. 24 e. v. een beschrijving voor van de hand van den toenmaligen Pastoor te Tandjong-Sakti, L. Jennissen, S. J., van een door hem bijgewoonde "spiritistische plechtigheid, welke in de taal der Pasěmahers, tielol genoemd wordt».

"Tilol» nu is één der vormen, waarin zich het shamanisme in de Pasěmah openbaart. De bedoeling van dit opstel is, om deze uiting van divinatie, waaraan dit bergvolk een bizondere waarde toekent, voor het opsporen van de gezindheid der hen omringende geesten, aan een nadere bespreking te onderwerpen. Hierbij zij vooropgesteld, dat in dit artikel bijna uitsluitend, gebruik is gemaakt van de aanteekeningen van den heer O. L. Helfrich, die destijds, als bestuursambtenaar in het Bengkoelensche, waardevol materiaal op volkenkundig en taalkundig gebied heeft weten bijeen te zamelen. Hetgeen men hieronder over tilol vindt opgeteekend, beschouwe men als een aanvulling van bovengenoemde interessante beschrijving van Jennissen. ${ }^{2}$ )

Tot «tilol» mag niet worden overgegaan, dan na verkregen toestemming van het margahoofd, terwijl het dorpshoofd van tevoren uiteenzet, waarover men het oordeel van de geesten wil inwinnen. In den regel geschiedt dit in gevallen van ziekte

1) Pasĕmah vulgo: „Bĕsĕmah”, afgeleid van de vischsoort „sěmah”, waarnaar de landstreek genoemd is. Hoewel in dit artikel enkel sprake is van de Pasermah, gelden deze gebruiken evenzeer voor de Sěrawaj-streken, alwaar meer speciaal "těnong" en "sir" beoefend worden.

2) Zie ook in den Borneo Almanak, 6 jrg. 1916, van Pastoor D. Verhoeven "Uit Sumatra's binnenland", waarin eveneens van een tilol-séance sprake is. 
en plagen en van "kěběndon», d. i. wanneer men getroffen is door den vloek van goden, geesten of voorouders. Een tilolséance neemt gewoonlijk tegen 8 uur in den vooravond "š̌kělap" boedaq», een aanvang en duurt vaak tot den volgenden morgen. Men pleegt het doesoenplein ervoor te bestemmen, dat voor zooveel noodig met matten wordt bedekt. Op één dezer matten, "lampik» geheeten, moeten van tevoren de volgende onontbeerlijke voorwerpen worden uitgestald, zooals op onderstaande teekening is aangegeven.

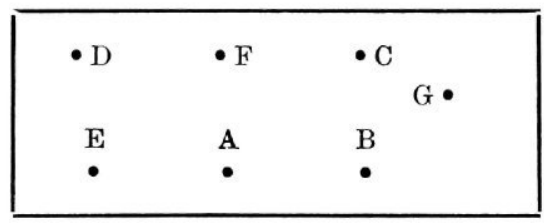

A. twee stukken nieuw wit katoen;

B. een kort zwaard, "pědang»;

C. een "bakol bětěrah», of ook wel "pětrah tali njawě»genoemd, inhoudende: een stuk lijnwaad, een streng wit garen en een wit kopje, gevuld met wat rijst, "padi běsaq"; aan het garen is een zilveren ring, dan wel een naald bevestigd. ${ }^{1}$ )

D. een wierookpotje, "doepě'an»;

E. een wit kopje met water;

F. een bord van den volgenden inhoud: A) 5 op elkaar gestapelde sirih-blaren, met de steeltjes naar boven gekeerd, "sigrīh djawě, waarop een gambir-blad is gelegd, voorzien van 5 vegen, "pajot", sirih-kalk. Hierop is een "lellěsong» geplaatst, d. i. een blokje "tjęndaně»-hout, in den vorm van een miniatuur rijstblok met 3 kuiltjes erin: in het middelste is water gegoten, de beide anderen bevatten respectievelijk een in klapperolie gedrenkt vlokje kapas en rijste-poeder, "borih». De «lělěsong» kan eventueel vervangen worden door 3 witte kopjes, "tjoebiq", welke in één rij worden geplaatst, en denzelfden inhoud moeten hebben, als de 3 openingen van de "lelěsong", met uitzondering van het middelste kopje, dat "ajiq tjĕndaně» bevat, d. i. water, met

1) Zie voor een uitvoerige beteekenis van de in het artikel voorkomende Pasēmahsche woorden en uitdrukkingen Helfrich's „Midden Maleische Woordenlijst” (Verh. Bat. Gen. v. K. en W. deel 53) met daarop gevolgde supplementen, terwijl voor de beteekenis van de "pĕtrah tali njawĕ" bovendien wordt verwezen naar mijn ,A Animistische gebruiken in de Paš̆mah" (Kol. Tijdschrift Sept. 1925). 
een stukje "tjěndanऍ̌-hout erin. Aan den eenen kant van de "lellěsong", c. q. kopje, waarin zich het vlokje kapas bevindt, wordt op het gambir-blad een takje "sělas $i$ " of "tjendanð», gelegd; aan den anderen kant een stroosigaret, "roekoq (飞)'ndjadi». Voorts treft men op het bord aan: B) 5 stukjes pinang, "pinang limě si(j)'ong" en tenslotte (C en D) 2 z.g. "sigrat sigrih», d. i. een sirih blad, in den vorm van een peperhuisje gevouwen, een met sirih-kalk bestreken gambir-blad, en een stukje pinang.

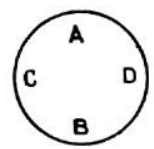

G. een schotel inhoudende: A) witte rijstepap; "boebogr bělantan» en B) 5 "lěmang gěmoq" d. i. zonder zout gaar gestoomde kleefrijst.

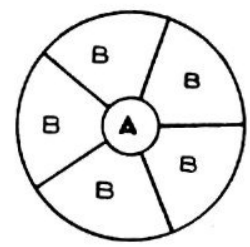

Dit wat het instrumentarium betreft.

Gelijk Pastoor Jennissen reeds opmerkte, zijn voor «tilol» ten minste 2 personen noodig. Allereerst het medium zelve, de z. g. «'ajam tilol» en zijn leider de «doekon tilol» of ook wel «ngoetjol 'ajam» genoemd. Het zijn uitsluitend mannen, die als medium mogen optreden. Het eenige vereischte, waaraan deze moeten voldoen is, dat zij spoedig in zwijm kunnen vallen. In den regel is in iedere marga wel zoo'n persoon aanwezig, die reeds eerder de bewijzen heeft geleverd voor medium geschikt te zijn. Voor het geval dat men door middel van «tilol, het oordeel der geesten wilde inwinnen, maar over geen geschikten "'ajam tilol» de beschikking had, ging men volgens Helfrich als volgt te werk. Alle doesoengenooten werden op het dorpsplein verzameld, waarop de "doekon tilol» één hunner uitkoos, van wien hij onderstelde, dat deze wel als medium zou kunnen dienst doen. Degene, die het onderzoek moest ondergaan (B) werd verzocht voor de bewuste "lampik» plaats te nemen, met 
de beenen kruislings over elkaar, "doedoq běsilaw», terwijl de "doekon" (A) achter hem kwam staan. B moest beginnen met zich de ooren af te sluiten door de, met kapas omwonden, duimen er tegen aan te drukken; de neusgaten moesten met de beide ringvingers worden toegestopt, terwijl de oogen met de wijsvingers werden bedekt. Eén der op het matje klaargelegde stukken wit $^{1}$ ) katoen werd hem voorts om het hoofd gewikkeld, waardoor het gansche gezicht bedekt was. A. nam dan het takje sšlasih» of "tjĕndaně» in de hand, lichtte vervolgens de om het hoofd van B. gewonden "ka'in pot $i \mathrm{~h}$ » een weinig op en fluisterde dezen eerst in het linker-, dan in het rechter oor een formule, waarin hij verklaart, dat de Radjě Njawě, de God̀ der zielen, uit het lichaam van den één of anderen lijder is gevaren en dat de Radje Djin, de God der kwade geesten, ervoor in de plaats is getreden; hij beveelt nu iemand die "sakti» is, d. i. met een bovennatuurlijk vermogen begaafd, om zich op weg te begeven, ten einde den Pojang Kĕtoenggalan, den algemeenen stamvader der Pasěmahers, te raadplegen. ${ }^{2}$ ) Nadat de "doekon tilol, B. aldus had ingefluisterd, stak hij het daarvoor bestemde strootje op, deed er eerst een paar trekken aan, nam dan zelf den aangestoken kant in zijn mond, stak B het andere einde in den mond, en blies hem aldus den rook in. Als dit tot uitwerking had, dat B. na eerst door al zijn leden te hebben getrild, in bewusteloozen toestand geraakte, dan had $\mathrm{B}$. het bewijs geleverd voor medium geschikt te zijn. Het kwam praktisch niet voor, dat onder de doesoengenooten geen persoon gevonden werd, die niet als «ajam tilol» dienst kon doen.

Ook voor de eigenlijke séance moet het gezicht van het medium geheel bedekt worden; speciaal oogen, neus en ooren worden toegestopt, en zulks gedurende het geheele verloop van de plechtigheid, terwijl hij eveneens berookt, "dibisiq" wordt. Voordat hij nu zijn tocht aanvangt, wordt hij met een takje

1) Opmerkelijk, vooral bij godsdienstige gebruiken, is de bizondere waarde, die wordt toegekend aan de witte kleur der voorwerpen, terwijl daarentegen een witte karbouw geenszins in aanzien staat. Men zal nimmer een karbouw van die kleur bestemmen voor een of ander feestmaal, daar zulks als verderfelijk wordt aangemerkt!

2) De tekst luidt: „potih koekoe 'itamnjë 'agrang masoq 'ograng, kĕloe,wagrlah 'angkaw Radjẻ Njawě, masoqlah 'angkaw Radjĕ Djin; 'akoe kan "njoeroh 'ograng sakti bĕdjalan (ẽ)'nggi Pojang Kĕtoenggalan!"

Dl. 82. 
"sělasih» c. q. "tjěndaň̌ op het hoofd geslagen en zegt de "doekon», dat hij zich op weg moet begeven, en dat zijn ziel moet opstijgen naar één der hemelen, waar de ziel uitgedreven wordt ${ }^{1}$ ). Hierop vangt de ''ajam tilol, zijn reis naar het geestes-land aan. Voor de wijze, waarop dit geschiedt wordt verwezen naar de beschrijving van Jennissen. De "doekon» gaat intusschen voort met hem met het takje "šelasih» op het hootd te tikken en zegt dan nogmaals, maar nu in andere bewoordingen, dat zijn ziel naar de zeven hemelen moet vertrekken ${ }^{2}$ ), Interessant zijn de ontmoetingen, die hij op zijn reis heeft, waarvan hij het publiek op gedempten toon mededeeling doet. Gewoonlijk ontmoet hij eerst een of ander wild dier, hetgeen hij aankondigt met de woorden: "koetermoe binatang grimbe», waarna hij ophoudt met het maken van schuivel- bewegingen. Niet zoodra merkt dit de *doekon" op, of deze maant hem aan om zich niet te laten afschrikken, niet op te houden, maar voort te gaan, zeggende: "djangan mandaq, Sidang Sali $\mathrm{h}$, tæegroslah, bedjalanlah kamoe!» Ook komt het medium wel te staan voor een "djambat goentong", d.i. een z.g. brug in aanbouw, waardoor de beide oevers van een rivier, c. q. kanten van een ravijn nog niet verbonden zijn. Het is weer de edoekon», die hem moed inspreekt door de woorden, «djangan mandaq Sidang Salih, loempati Sidang Salih». En grappig is het te zien, hoe Sidang Salih een weinig van den grond opwipt, alsof hij inderdaad den sprong maakt. Al verder komt hij tegen een "kawah didih", d.i. een ijzeren pan, gevuld met gloeiende vloeistof, dan een "( ()$^{\prime} n$ tadoe (๕)'mbaq koelak», dat is een rups ter grootte van een "koelak»; voorts geesten van hen, die op abnormale wijze gestorven zijn, zooals "mati kagrot», d.i. tijdens de zwangerschapsperiode en binnen den termijn van 40 dagen na de bevalling,

1) "těrdjalanlah Sidang Salih" - d.i. de naam waarmee het medium wordt aangesproken - „Sidang Salih mĕlajang sakti mĕnĕngah padang Raboe Samat, „Samat sěmĕdong samě diwě, měndjaring di poentjaq ni(j)'ogr, (mě)'ngěně "'anaq ramě ramě, těbaring sěroepě tidoq, njawě ka(n) tandang kĕsĕrgě, nasi "sěkěpal di sěgoeron di poelaw ramĕ, 'oembaq běsaq' 'angin kan toegron, di "saně djalan bĕrombaq njawĕ".

2) „měndjaring djaring di goedong ni(j)'ogr, kĕně boegrong rawěrawĕ, „tĕbaring sěroepě tidoq, Sidang Salih ka(n) tandang kĕsĕrgě, na'iq kĕsĕrgĕ "toedjoh".

Van deze teksten is slechts een vrije vertaling te geven, daar een letterlijke overzetting geen zin heeft. 
"mati pědjěř», d.i. door een onheil getroffen, enz. Daarna volgen de ontmoetingen met diverse kwade geesten, "djin's, zooals de "djin grimbě, "djin' ajiq», enz. Bij elke ontmoeting krijgt men dezelfde vertooning te zien: het medium schrikt op, houdt even stil, waarop de "doekon» hem zegt geen vrees te toonen en hem tot voortgaan maant, bij zijn woorden ${ }^{1}$ ) kracht zettende door den «ajam» hetzij op het hoofd, hetzij op de schouders met het takje "šllasih" of "tjęndanऍ» te slaan. Wanneer het medium in zijn bewegingen zoo heftig wordt, dat hij tegen de omstanders dreigt te botsen, manen deze hem tot kalmte, door, met de vlakke hand op den grond slaande, uit te roepen: "haj, badan, badan!» hem aldus waarschuwende, dat hij tegen menschen, lett. lichamen, aankomt, waarop hij naar het midden van den kring terug schuift.

Ten langen leste komt hij in het land, waar de geesten verblijf houden en kan hij dus overgaan tot het inwinnen van hun raad. Vaak is het de Pojang Kĕtoenggalan, ook wel Pojang Pagar Besi genoemd, tot wien men zich om inlichtingen wendt, en die door het medium aldus wordt aangesproken: «Ik ben tot U gekomen, Pojang Ketoenggalan, daartoe afgevaardigd door mijn doesoengenooten om $\mathrm{U}$ te melden, waarom wij tot tilol zijn overgegaan en verzoeken $U$ om van ons het gevaar af te wenden ${ }^{2}$ )».

Van dit oogenblik wijzigt zich de rol van de "ajam tilol». Het is nu de Pojang, die zich in het medium manifesteert, na inmiddels in hem te zijn gevaren. Hevige stuiptrekkingen moeten als bewijs dienen van deze inbezitneming. Het is dan ook de Pojang, die nu vraagt: "wie ontbiedt mij?» ("si(j)'ape koengkon?»). Deze vraag wordt door den «doekon» beantwoord met de woorden: "wij allen hier aanwezig" ("kami banjaq gale gale!»). Vervolgens brandt hij wierook voor het medium, dat nu zijn bewegingen gestaakt heeft; enkel tijdens het spreken van den Pojang krijgt hij hevige stuiptrekkingen. Het branden van wierook gaat samen met het opdreunen van de volgende "serram» ${ }^{3}$ ): "de ajam is nu * hier aangekomen, moge de Pojang hem ontvangen, en hem niet "afstooten; met wien wenscht gij te spreken, het zijn hier allemaal

1) „bědjalanlah tĕgros Sidang Salih, djangan tamban, djangan takot!",

$\left.{ }^{2}\right)$,'akoe datang Pojang Kĕtoenggalan, di koengkon 'ograng banjaq sěgalě „sěgrĕpat doeson laman, sangkan .... (de reden van het onheil), toe'apě halnjĕ, ,mintaq toelagri (è)'nggagri pojang.

s) e.s. v. formulier. 
uw kinderen en kleinkinderen $\left.{ }^{1}\right)$. De Pojang roept dan kort af: "wat wilt ge?» ("ap̌ kendaq?»), waarop de "doekon, wederom vraagt: "met wien wenscht $U$ te spreken?» ('ngan sap̌̌ přrambaq?»). De Pojang roept alsdan den naam af van één der omstanders, die door den "doekon tilol» wordt uitgenoodigd naar de "gagrang» ${ }^{2}$ ) van de woning van den lijder te gaan, ten einde zich voor deze plechtigheid eerst te reinigen, of zooals het heet "b̌bbasoh tangan ngan kěting, běgroesap ngan běkoemogr», lett. zich handen en voeten, zoomede het gezicht te wasschen en den mond te spoelen. Bij terugkomst moet hij de plaats van den "doekon» innemen, wierook branden en een formulier uitspreken, dat hem woord voor woord door den doekon wordt voorgezegd en hetgeen zooveel beteekent als: «de ajam is nu aangekomen bij $\mathrm{U}$, Pojang, om $\mathrm{U}$ te verzoeken het onheil, waardoor wij getroffen zijn (omschrijving van het onheil) van ons af te wenden, wil ons mededeelen welke schuld wij hebben begaan, waardoor ons een en ander is overkomen! ${ }^{3}$ ) In den regel moet dit verzoek meerdere malen worden herhaald, alvorens de Pojang zijn antwoord geeft.

Als de meest voorkomende oorzaken werden tenslotte opgegeven: het nog schuldig zijn van een zoenoffer in gevallen van overspel, buitenechtelijke gemeenschap, moord of doodslag, "'adऍlah, gawi ketinggalan'ndiqdð běsijang»; het zweren van een valschen eed, "soempah (an) salah»; het niet zijn nagekomen van een, aan de Goden gedane, gelofte, «',adelah sangi (e)' "'ndiqde di bajigr»; omdat gestolen goederen geheeld zijn, "'adऍlah salah (mÆ)'nggadoh lapan sěmbahan»; omdat het hoofd onrechtvaardig is geweest, "ngibagr mergě»; cmdat een hoofd zwaar gekneveld heeft, "kědok kědalam timbऍ kěloewagr dimane, "goendjaq direnggot», enz. De aanwezigen zijn nu één en al spanning; vooral de familieleden van de(n) zieke zijn door schrik bevangen. Het gebeurt dan ook niet licht, dat men het ten laste gelegde feit niet erkent. Heeft-de Pojang als reden van de ramp of ziekte b. v. opgegeven, dat aan een gelofte nog niet is voldaan, "sangi (๕)' ndiqde diba'igr», dan wordt hem nader gevraagd,

1) ,sěram maq'lajkom, sěram, běrkat Pojang Kětoenggalan, 'ajam 'inilah sampaj, „mintaq sěkapkannjě pade Pojang, mintaq djangan toelagri, njělah ngan "sapě kamoe ka(n) perrambaq, 'anaq tjoetjong kamoe sěgalē-galě 'ini".

2) platform.

s) "'ini 'ajam lah sampaj (mẽ)'nggagri Pojang, mintaq toelagri salah kami, "toe(w)'ape sangkan kami groesaq njěmbah toe(w)'apě kěsalahan, mintaq "toedoh ka(n) lih Pojang". 
welke gelofte niet is voldaan, "sangi apě (๕)' ndiqde ma'igr?», en luidt het antwoordt hierop b. v., dat de grootouders (van de(n) zieke) geen karbouw hebben geslacht om de gelofte na te komen, "niniq kamoe (๕)' ndiqde ma' igr sangi njěmbělih kěbaw», zoo geven belanghebbenden al schreeuwende te kennen, dat het gevraagde offer alsnog spoedigst zal worden gebracht, zoodat de Pojang over niets meer te klagen zal hebben, daarbij tevens vergiffenis vragende voor hun schromelijke nalatigheid ${ }^{1}$ ). Is door den Pojang geantwoord: “'adě gawi kětinggalan» dan wordt hem de vraag voorgelegd, welk offerbeest moet worden geslacht om de zonden op te heffen; bij adatdelicten wordt hem verzocht te willen opgeven, welke offermalen moeten worden aangericht, terwijl bij diefstal de ontvreemde goederen onmiddellijk door den schuldige moeten worden gerestitueerd.

Tot besluit wordt den Pojang de vraag gesteld: "ade salah "la'in ?» waarop doorgaans het antwoord volgt: "(๔)'ndiqdऍ "lagi, oedě!». Niet zoodra is het laatste woord uitgesproken of het medium valt bewusteloos neer. De "doekon" neemt alsdan het kopje met tjendaně-water en wrijft hem hiermee eerst den rechter-, dan den linkerarm en vervolgens de voeten in. Als er beweging in de ledematen valt te bemerken, blaast de "doekon tilol», het medium in de ooren, eerst weer in het linker, dan in het rechter oor, en fluistert hem in, dat de kwade Radje Djin niet langer in het lichaam van $\operatorname{de}(\mathrm{n})$ zieke huist, maar dat diens plaats weder is ingenomen door den Radje Njaw̌, wien gevraagd wordt goed voor de ziel van den lijder te waken ${ }^{2}$ ). Het medium komt dan spoedig daarop tot bewustzijn, en de tilol-séance is afgeloopen.

Het is nu zaak om het door den Pojang gevorderde offermaal aan te richten, waarbij in een uitvoerige "serram» nogmaals schuld moet worden bekend en vergiffenis aan de Goden moet worden gevraagd ${ }^{3}$ ).

1) ,baiqlah, mintaq. 'ampon kěpadě pojang, sangi 'itoe lih kami di ba'igr

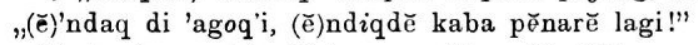

2) „koekoe potihnjě 'agrang 'itamnjě, kěloewagrlah 'angkaw Radjě Djin, ,mąoqlah 'angkaw Radjē Njawě, haj djagě Si'anoe!"

3) sěram maq'lajkom, sěram běrkat Pojang Kětoenggalan, Si Anoe (naam

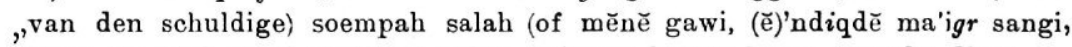
,enz.) na kini kami mělipati salab, mintaq loepot lěpas kĕpade diwě... "(namen der onderscheidene goden), kĕpadĕ Pojang Kĕtoenggalan", enz, 
De «'ajam tilol, wordt voor de bewezen diensten onthaald op een overvloedig maal, terwijl hem voorts de twee stukken "ka' in potih» en 10 stuks lëmang ten geschenke worden gegeven. Ook de "doekon» wordt voor een rijk maal genoodigd, die dan nog in den regel, eenig geld, tot een maximum bedrag van een rijksdaalder, in ontvangst heeft te nemen. Men is evenwel niet gehouden om hem dit te betalen.

Naar het oordeel van Jennissen heeft men in "tilol» niets anders te zien, dan "een naäperij van hetgeen de eigenlijke "shamanen in den Indischen Archipel doen, en derhalve een beet"nemerij van den zoogenaamden ajam», die zelfs van bedrog beticht wordt. Deze uitspraak lijkt mij allerminst gegrond. Uiteraard zal de geleidelijke islamiseering van de Pasěmah-streken deze oud-Heidensche gebruiken op den achtergrond dringen, doch dat het shamanisme hier een povere nabootsing zou zijn van deze wijze van geestenbezwering elders, waarbij in de allereerste plaats aan een opzettelijke beetnemerij gedacht moet worden, is een uitspraak, welke op geen enkel aannemelijk feit is gebaseerd. Reeds Wilken heeft zich aan het slot van zijn verhandeling «Het Shamanisme bij de Volken van den Indischen Archipel» (Deel III der Verspreide Geschriften, bld. 325-396) de vraag ter beantwoording voorgelegd in hoeverre de shamaan bij zijn verrichtingen te goeder trouw of willens en wetens een bedrieger is, waarbij deze groote Geleerde dan tot de conclusie komt dat «wij "mogen aannemen, dat bij al hetgeen de shamaan bij de volken "van den Indischen Archipel, in den toestand van bezieling ver"richt, geen moedwillig bedrog in het spel is", een meening, die Mr. Van Ossenbruggen in zijn noot op blz. 396 ten volle onderschrijft met de woorden: "Aan de goede trouw van de shamanen "en toovenaars der minder beschaafde volken valt $\mathrm{m}$. i. even "weinig te twijfelen als aan die van de meeste onzer mediums "op spiritistische séances». En mij dunkt, er is geen reden om aan te nemen, dat de Pasermahers in deze een uitzondering zouden zijn op de overige volken van den Indischen Archipel!

Een andere vorm van shamanisme is "moetos gentong», dat evenals "tilol» gerekend wordt te behooren tot de z. g. "agoq běsaq" lett. vertaald "groote werken», d.w.z. dat deze methoden van geestenbezwering alleen worden toegepast als het gaat om opsporing van belangrijke ongevallen, ziekten of plagen. Hetgeen dan ook op een dezer twee wijzen aan het licht wordt gebracht 
moet tenminste met een geiten-offer worden "schoongewasschen ». Doorgaans echter wordt een karbouw gevorderd.

In tegenstelling met "tilol» is voor "moetos gentong" geen leidsman noodig, terwijl als shamaan ook vrouwen kunnen optreden. $Z_{\mathrm{ij}}$ die hiervoor geschikt zijn, worden geacht van een hoogere orde te zijn, dan de "ajam tilol». Zij moeten speciaal voorbeschikt zijn, en dragen den titel van "pěnditě» of "rěbijah", de meer algemeene benamingen voor vaardige mannelijke en vrouwelijke "doekons».

Ook het «instrumentarium» wijkt eenigszins af van hetgeen voor een "tilol»-séance benoodigd is. Het bestaat uit:

a) twee stukken nieuw wit katoen;

b) een "bakol běterah»;

c) een wierook-potje;

d) een soort kussen, dat met wit goed is overtrokken;

e) een wit kopje met "tjěndaně»-water, welke voorwerpen op een matje worden klaargelegd.

"Moetos gentong" kan ook binnenshuis plaats hebben. De shamaan, hier kortweg "'ajam» genoemd, begint met zich in het wit te hullen: daartoe slaat hij een dier lappen "ka'in potih" om de lendenen, de andere over de schouders, terwijl hij als hoofddoek eveneens een stuk wit goed gebruikt. Hij neemt vervolgens voor het matje plaats, en vraagt van tevoren, waarover men het geestes-oordeel wenscht in te roepen. Het is de «djoeraj toewě, d. i. de drager van den oudsten tak van het geslacht in het dorp, die hem dan uitvoerig uiteenzet wat de aanleiding is, dat men tot "moetos-gentong, zijn toevlucht neemt. Hierop doet hij wat wierook op het vuur van de "doepě-an», en onder het prevelen van eindelooze "serram's», waarin de Pojang Kětoenggalan, de Diwě noegronka(n) kěboemi», Diwe nating njawě en de Diwě 'andassan, welke laatste als de beschermgeest van de doesoen wordt vereerd, wederom een groote rol spelen, snuift hij de wierook in, daarbij met het boven-lichaam zacht op en neer wiegende. Na eenigen tijd valt hij als een blok omver. Het is weer de djoeraj toewe», die zich haast om hem op het kussen te slapen te leggen. De doek om de schouders wordt hem voorzichtig afgewikkeld en wordt dan over het medium uitgespreid, dat met opgetrokken knieën liggen blijft. Men krijgt dan een soortgelijke voorstelling te zien als bij «tilol». De «'ajam» moet ook weer een heelen tocht ondernemen, alvorens hij in de 
geestenwereld belandt. Ook hier wordt de eigenlijke naam van het medium verwisseld tegen een "djoeloq njawě», een zielenaam. De ontmoetingen, die de shamaan op zijn reis heeft, zijn van denzelfden aard, als bij de beschrijving van een «tilol»sèance reeds werden behandeld. Meermalen is hij in een hevigen strijd gewikkeld met diverse booze geesten, e. d., hetgeen hij aangeeft door een verward geschreeuw. Hier is geen "doekon", die hem moed inspreekt; hij moet zelf maar zien de tallooze gevaren te overwinnen. Is hij eindelijk zoo ver, dat hij de betrokken goden of geesten heeft aangetroffen, dan stelt hij deze in kennis met het geval, waarover men gaarne hun oordeel zou willen inwinnen. Kort hierop daalt de aangesproken "Pojang» in het lichaam van den shamaan neer, en met barsche stem vraagt hij den "djoeraj toewě van de doesoen, wat men van hem begeert. Deze herhaalt dan wat hij, bij den aanvang van de séance, het medium heeft uiteengezet, en zoo ontspint zich het gesprek tusschen "Pojang» en "djoeraj toewě". Tenslotte komt men tot een zelfde resultaat, als we reeds bij "tilol» leerden kennen. De schuld is weer meestal gelegen in het "(̌)'ndiqde besi(j)'ang gawi», enz.

Als eindelijk de "Pojang" het lichaam weer verlaten heeft, roept men den shamaan heel voorzichtig bij zijn naam, ontdoet hem van het dekkleed en maseert hem het lichaam, en meer speciaal de ledematen, die absoluut verstijfd zijn met «tjęndaně»water. Langzaam komt de "'ajam» $b i j$, die voorgeeft in een diepen slaap gewikkeld te zijn geweest. Het is ook hierbij gebruik de shamaan de stukken wit goed als belooning mee te geven en hem nog nader te onthalen.

Als staande in een nauw verband met deze specifiek shamanistische gebruiken, moeten hier in de derde plaats worden genoemd de onderscheidene vormen van "tenong", waaronder men een soort van wichelarij heeft te verstaan. Al naarmate men daarbij gebruik maakt van padi-korrels, van een houweel, «běli(j)'ong», rotan "oewi», een fuik «boeboe» of van "pinang» enz. spreekt men van «těnong padi», těnong běli(j'ong, těnong oewi, enz. Ook voor těnong is een vergunning vereischt van het marga-hoofd, terwijl het doesoen-hoọfd of diens gemachtigde de séance, welke in het publiek plaats heeft, moet bijwonen. Alvorens daarmee een begin wordt gemaakt, zet het doesoenhoofd aan de toeschouwers het doel ervan uiteen, 
Er wordt in het algemeen ge-těnong-d:

$1^{\circ}$. wanneer men de oorzaken wil opsporen van ziekten, welke ondanks alle mogelijke pogingen, maar niet willen wijken, het z.g. "něnongka(n) bale sakit";

$2^{\circ}$. om te weten te komen, wie in een bepaald delict, meer speciaal in een diefstalzaak, betrokken is, het z.g. "měnongka(n) perrkare»;

$3^{\circ}$. om na te gaan of een terrein, dat men voor het stichten of verplaatsen van een doesoen wil bestemmen, al dan niet daarvoor geschikt is, het "nenongka(n) badah doeson";

$4^{\circ}$. wanneer men wil weten of een droom, dan wel een bericht uit verre landen ontvangen, al dan niet gunstig is, of wel, wat het lot is van verwanten, die veraf wonen, en die men daarom zelden bezoekt, het z.g. "něnongka(n) mimpi» c.q. "nenongka(n) běritě dja'oh,;

$5^{\circ}$. wanneer een jongeling, c. q. een meisje, of wel de respectievelijke ouders willen weten of het meisje, c. q. de jongeling op wie(n) men zijn keuze gevestigd heeft, al dan niet een goede partij zal zijn, het "něnongka(n) boedjang ngan gadis».

$6^{\circ}$. om te weten te komen of buitenechtelijke gemeenschap heeft plaats gehad bij «kěběndon», eveneens genoemd: "něnong$\mathrm{ka}(\mathrm{n})$ boedjang ngan gadis».

De séance wordt geleid door 2 personen, de «doekon těnong», meestal een bekwaam geneeskundige, die tevens op de hoogte is van de onontbeerlijke "sěram's" en een soort van medium, dat voorbeschikt is, als werktuig der goden dienst te doen. Aaneengesloten wenkbrauwen worden geacht een uiterlijk kenteeken te zijn van deze eigenschap.

Waar de verschillende vormen van "těnong» nagenoeg aan elkaar gelijk zijn, wordt hier alleen "tennong padi» wat uitvoeriger behandeld, waarvoor temeer reden bestaat, daar dit tevens het meest voorkomende genre is. Hiervoor nu heeft mer noodig de padi-korrels van een goed gevulde aar, welk voor dit doel van den halm wordt afgebroken. De padi mag niet eerst uitgetreden worden en wordt zoolang in een wit kopje bewaard; verder één "kěladi»- of "kěmboelaw»-blad, een takje "sělas $i h$ " en één van "tjęndaně» of "kěmoening» hout. Dit alles tezamen noemt men de "ramoe(w)'an těnong». Hoewel niet direct benoodigd voor de séance zelve, moeten hier bovendien nog worden bijgezet de gebruikelijke "padang pegri(j)'ăsan» $\left.{ }^{1}\right)$,

1) een kopje met water, waarin een stukje tjændanĕ-hout; een kopje, inhoudende 
"sigrih 7 lambagr», 7 "pajot kapogr», 7 «si(j)'ong pinang» en 7 "gambigr" bladeren. De voor tenong te bezigen voorwerpen moeten, alvorens als zoodanig te kunnen worden gebruikt, eerst worden belezen, hetgeen men in de volkstaal "tawar» noemt. ${ }^{1}$ ) Voorts moeten bij den aanvang van de séance de padi-korrels, c. q. de andere voorwerpen, op een "kadjang» of "djalit», d. i. een soort van mat, worden gelegd en met een "kemboelaw»-blad worden toegedekt.

Degene, die een "doekon těnong» noodig heeft om in een ziektegeval b.v. een uitspraak van de Goden uit te lokken, komt tot hem met de mededeeling, dat hij het benoodigde voor een »těnong»-séance reeds heeft bijeengebracht; hij vraagt nu den "doekon" tot "těnong» te willen overgaan, om de reden op te sporen van de ziekte, waaraan de betrokken persoon lijdende is; mocht deze een fout hebben begaan, dan zal deze onverwijld worden hersteld. ${ }^{2}$ ) De "doekon» antwoordt hem dan, dat hij toestemt in de gevraagde "těnong"-séance, dat hij wierook zal branden en heil voor de(n) zieke zal afsmeken, opdat deze zal herstellen. ${ }^{3}$ ) De "doekon» gaat dan over tot het branden van wierook, hierbij een "š̌ram» uitsprekende, waarin hij ongeveer zegt, dat hij overdag noch 's avonds de Goden aanroept of wierook brandt, maar dat hij thans, onder aanroeping van diverse Goden en geesten, hun hulp zal inroepen voor de(n) bewuste(n) zieke, hun zal vragen welke fout hij begaan heeft, wat voor een offermaal zij wenschen, opdat de patient zal genezen. Tevens vertelt hij, hoe of de «těnong» ontstaan is, de z.g. "'oesoran těnong», en in welke gevallen těnong moet worden toegepast. ${ }^{4}$ ) Daarop legt hij een wijle zijn rechterhand op het

een mengsel van geraspte kurkuma, sirihkalk en olie, een kopje met water waarop o. m. een melatibloem.

1) De formule luidt: „,sěnaq kaloe di goenong bikoe sě bikoe, doe(w)ě soendē, „kětigě 'ograng soegib, kěmpat 'ograng pingaj, kělimě diwě (pē) těnong(an) "'ingat 'angkaw sikat përdjandji(j)'an t ‘kalē di goenong bikoe", waarvan slechts voor de laatste zinsnede eene begrijpelijke vertaling te geven is.

2) ,akoe'ini moewat padang pěgri(j)'ăsan sěrtě ngan ramoe(w)an těnong; „(e))'ndaq mintaq boekaqka(n) těnong lih ograng 'ini (naạ̣ v. d. zieke) tětang„gong 'idapan; kaloe adě salah sěsat (ě)n'daq di běnagri, salah (ě)'ndaq di „,kělipati (ě)'ndaq mintaq těnong lantang sělantangan (厄)'ndaq djadi".

3) „těnong lantang pajoe, lih kěmennjan (ě)'ndaq di silap, lih těnong (ě)'ndaq „diboekaq, (mē)'nggajoe badjik gagri 'ograng (ē)'ndaq mintaq lantang".

4) "sěram maq'lajkom sěram, těkalě 'agri těkalě malam (e) 'ndiqdě 'akoe njěbot „běsĕram, (ě)'ndiqdě 'akoe pasang pěrasapan, sěpětang 'ini 'akoe njěbot.diwe 
"kěmboelaw»-blad, waaronder de padi-korrels zijn verborgen, neemt dan een paar korrels in de rechterhand, sluit die hand, blaast op de vuist en verzoekt dan de rijstgodin tot "těnong" over te gaan, en dat deze "těnong" een goed resultaat moge opleveren. ${ }^{1}$ ) $\mathrm{Na}$ nogmaals op de vuist te hebben geblazen worden de padi-korrels weer bij elkaar gevoegd en door elkaar geschud op de "kadjang»-mat of "djalit». De "doekon» neemt alsdan het blad in de linkerhand, terwijl hij met de rechterhand aan den binnenkant van het blad een kruis aanbrengt met het van olie doortrokken vlokje katoen en een weinig kurkuma van de "padang pěgri(j)'ăsan", waarna de padi-korrels wederom met het blad worden bedekt. Ook het takje "sělasih" of "tjęndaně" ondergaat een geheimzinnige bewerking: het wordt onder het prevelen van "serram's" boven de wierook gehouden, vervolgens in het kopje met "tjendaně»-water gedompeld, enz. Is deze ceremonie afgeloopen, dan noodigt de «doekon» het medium uit de rechterhand plat op het "kěmboelaw»-blad te plaatsen; hij zelf neemt dan het "sělasih»-takje in de hand en daarmee op het blad slaande, stelt hij de benoodigde vragen, waarop hij het antwoord verwacht door het zich verspreiden, "bepisar» van de padi-korrels. Hij vangt zijn vragen aan met deze inleiding: "Verheven "těnong», gij «těnong» van de Goden, het menschdom

„nating njawě si anoe, 'ograng noegronka(n) kěboemi, 'ograng moe(w) 'ătka(n) ,'idapan, diwě toegron ganti, mělikat groemah, 'ini mělikat (ê)'mpaj, mēlikat lamě, "djěměnang diwě, (mě)'nggagri (di) goenong, (mě)'nggagri diwě sěbakas, diwě „ka(n) migang tĕnong, (mê)'nggagri diwě toedjob, djadi sikat (ě)'ndiqdě těbilang „lih koe, sikat (ě)'ndiqdě těrataj, kaloe tědoeloe těmědi(j)'ăn běpapah běbim. bingan kamoe ini, têloenggoq těpětoenggal kamoe, 'akoe ngatorkan kěrdjěăn, "lih si 'anoe têtanggong lih bidapan, kaloe (ě)'mpoq gěgoedan kamoe, ka"loe'adě s`sat, kaloe 'adě salab, kaloe 'adě kěkěndaq'ăn kamoe, (e)'ndaq sědě„kahan běsaq magrě, kětjiq magrě, sěpi idapan boedaq'ini waras, roebě njēbot ,pantaw kamoe, 'itoelah padang pĕgri (j)'ăsan, makan sigrih makan pinang, „kamoe běborih běminjaq bětjěndaně, kamoe běri(j)'ăs běgranggoe kamoe ini, ,'akoe ka(n) ngoesorkan moelě těnong'itoe bělom 'adě, pěnditě bělom 'adě, ,rěbi(j)ăh měndang bĕlom 'adē, njēlah bikoe mirah maně moenggah kěgoenong „bikoe, bětoendong da'on kěmboelaw běsoemping sělasih i'tam noendaq'i padi

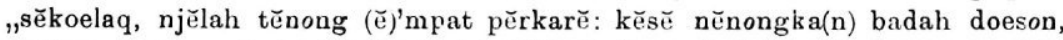
"kědoewě něnongka(n) běritě dja'ob, kětigě něnongka(n) boedjang ngan gadis, „kēmpat něnongka(n) balě sakit, njělah boedaq'ini tětanggong kěpadě balě

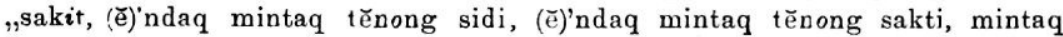
"tĕnong sělantangnje, sěram." Zie voorts den tekst in de bijlage hierachter.

1) „oooot, bĕtěri Sĕri (d.i. de dewi Seri der Javanen) radjě padi toenggang ,'anaq 'oemat bětanjě mintaq těnong sidi, mintaq těnong sakti, mintaq "tĕnong sělantangan." 
van God zit in moeilijkheid, het wenscht den Goden van de "těnong" iets te vragen; wanneer de voorwerpen, benoodigd voor tenong reeds gezuiverd en schoon zijn, laat ze dan uit elkaar gaan. ${ }^{1}$ ) Hieruit blijkt, dat het instrumentarium dus gezuiverd moet zijn, alvorens tot het beoogde doel te kunnen worden gebezigd.

Wanneer geen beweging komt in de korrels, c. q. houweel, enz. dan geldt dit als een bewijs, dat de voorwerpen niet voldoende gereinigd zijn, in welk geval alsnog tot het reinigen daarvan met zuiver water wordt overgegaan. Vervolgens gaat hij over tot het stellen van de eigenlijke vragen, aldus aanvangende: "gij, God"heid, die over "těnong» te zeggen hebt, misleidt ons niet; moet "de oorzaak van de ziekte worden toegeschreven aan den "diwě "di laot», God van de zee, zoo ja verspreidt $U$ dan» 2) Mocht de "ragam", lett. wat door kwade geesten wordt veroorzaakt, niet op rekening kunnen worden gesteld van den "diwe di laot», dan komt er geen beweging in de padikorrels. Telkenmale wordt voortgegaan met het slaan op het «kemboelaw»-blad, gevolgd door de vraag, of de ziekte moet worden toegeschreven aan den invloed van den een of andere Godheid, "ape ragam diwě.... , waarbij de «doekon» de verschillende hem bekende Goden de revue laat passeeren, om eventueel ook nog te rade te gaan bij de onderscheidene geesten, inz. de "mělikat pojang", totdat bij het vermelden van een dier "diwě» c. q. "mělikat pojang" de padikorrels zich bewegen, hetgeen als een onmiskenbaar teeken geldt, dat men bij die Godheid, geest, is beland, die de ziekte veroorzaakt heeft. Dan wordt de betrokken Godheid, enz., afgevraagd, wat de zieke misdreven heeft: of hij gezondigd heeft tegen de goede zeden of tegen bepaalde verbodsbepalingen,

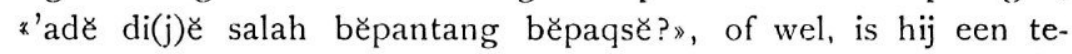
voren gedane gelofte niet nagekomen, heeft hij niet op het geschikte tijdstip geofferd of het offermaal niet naar behooren doen bereiden, "(๕)'ndiqdऍ (mと)'mba'igr sangi», enz. De betrokken "diwě», gelieve dan op te geven, of hij op een offer-

1) „kěsidi těnong, kaw těnong, těnong diwě, těnong diwatě, sertě 'oemat ,'allah těkědan boentoe, (ě )'ndaq bětanjě kěpadě diwě těnong, lah tjoetji lah „bantji sěgrkaj (pě)těnong(ăn) 'ini, 'amonlah tjoetji lah bantji běpisarlah kaw ,těnong."

$\left.{ }^{2}\right)$,sidi, sidi sakti sangjang radjě tĕnong, boelaq djangan, bandjoran djangan, „pěrboe!ě djangan, běběri(j)'ăt djangan”, -- hier komt de eigenlijke vraag "apě ragam diwe di la'ot, kaloe - - ragam diwě di la'ot pisarlah, těnong", 
maal gesteld is, c. q. welk offermaal. Anders wordt gevraagd of de ziekte door geneesmiddelen moet worden gecureerd, zoo ja, welke geneesmiddelen de (n) zieke moeten worden toegediend. Om op deze vraag een antwoord te erlangen somt de "doekon" alle hem bekende geneesmiddelen op, totdat het «bepisar» van de padikorrels aangeeft, dat een juist genoemd middel door de Goden wordt aangeraden. Met bekwamen spoed wordt dan aan dien wensch van "diwe», "mellikat» of "pojang» gehoor gegeven: het offermaal gebracht, het geneesmiddel bereid en de(n) patient toegediend. Blijven de padikorrels onbewegelijk, dan moet men zijn toevlucht nemen tot "tilol» of "moetos gentong», en bereikt men ook hiermee geen resultaat, dan is de zieke ten doode gedoemd!

Geldt de těnong-séance het opsporen van den dader in een diefstalzaak b.v., het z.g. "nenongkan perkare»", dan doet het hoofd van tevoren mededeeling, dat "tenong" plaats zal hebben, omdat een bepaalde doesoen-genoot bestolen is geworden; hij noodigt de omstanders uit om, ingeval één hunner door middel van těnong als dader mocht worden aangewezen, zich aan die uitspraak te onderwerpen, opdat er geen twist uit zal ontstaan ${ }^{1}$ ), waarop allen dan eerst moeten antwoorden, dat zij de uitspraak zullen aanvaarden. Indien de dief zich onder de aanwezigen bevindt zullen de padikorrels, c. q. houweel, rotan, enz., zich ongetwijfeld bewegen in de richting, waar deze zich bevindt.

De onderscheidene vormen van těnong gelijken in hoofdzaak op de hierboven beschreven "těnong padi», met dat verschil natuurlijk, dat de padi-korrels vervangen worden door een stuk rotan, een houweel, fuik, enz. ${ }^{2}$ )

1) „na kini ka(n) boekaq těnong, sangkan něnongka(n) si'anoe poenjě barang „kělěngitan, kaloe sěkirěnjě si(j)'apě sadjě nan di sěbotka(n) dēngan těnong ,'ini, kělě di(j)'ělah nan 'ambiq pěrkarě 'itoe, djangan (mě)'ndjadi sělang "sělisih."

2) Wel te onderscheiden van deze shamanistische wichelarij, kent men ook nog de "těnong tjintjin" waaronder men een soort kinderspel heeft te verstaan, bepaaldelijk tusschen de „boedjang-gadis". Een "doekon" is hierbij niet van noode, evcnmin de „ramoe(w)'an, těnong, enz. In het kort komt het spelletje hierop neer: men neemt 2 dunne, zilveren ringen, die men voor ongeveer $\frac{3}{4}$ gedeelte in katoen wikkelt, en dan in een kopje met water doet. Men zorge er voor, dat de ringen blijven drijven. Wanneer men nu wil weten of boedjang A met gadis B zal trouwen, roert men eerst flink in het kopje, dekt het tijdelijk toe, en ziet na eenigen tijd, of de niet omwonden gedeelten van de twee ringen al dan niet tegen elkaar zijn gestooten. Dit levert dan het antwoord op de gestelde vraag. 
Tot besluit nog een kleine uitweiding over een zeer bizondere methode om ziekten op te sporen, waartoe men zijn toevlucht neemt, alvorens door "těnong", en in laatste instantie door "tilol * en "moetos gěntong, het godsoordeel wordt ingewonnen. Men past haar uitsluitend toe voor ziekte-gevallen, waarbij maar geen beterschap schijnt in te treden. De "doekon» past alsdan de z.g. "sir"-proef toe. Onder "sir" heeft men te verstaan een duidelijke aanwijzing, die de "doekon» krijgt, zich openbarende in een ijzig gevoel of rillingen door het geheele lichaam, ten teeken, dat hij, bij het winnen van het gods-oordeel, aangaande den aard der ziekte, de oorzaken daarvan, enz. op het spoor is. Eerst wordt door de "doekon", onder het branden van wierook, bij de verschillende Goden navraag gedaan, wie onder hen de ziekte veroorzaakt heeft. Evenals bij "těnong» worden ook hier de onderscheidene Goden, enz. opgesomd, met verzoek echter den "doekon» rillingen te bezorgen, wanneer hij bij de ware Godheid is aanbeland ${ }^{1}$ ). Heeft de "doekon den juisten "diw飞" aangeroepen, dan wordt weer gevraagd, waardoor hij zich den toorn der Goden op den hals heeft gehaald, en op welke wijze genezing zoude kunnen intreden, enz. De Godheid antwoordt op de hem gestelde vragen, door den "doekon» steeds rillingen te bezorgen, in welk geval de "sir»-proef aan de verwachtingen heeft voldaan. In het ontkennende geval, als dus de "doekon» niets voelt, zal de "doekon těnong» moeten worden ontboden, en kan onk deze aan de Goden geen uitspraak ontlokken ${ }^{2}$ ), dan kunnen nog slechts "tilol» en "moetos gentong" redding brengen.

Den Haag, Mei 1926.

1) „sěram maq'lajkom sěram, njěbot kamoe pantaw kamoe njěbot kamoe „, sidi njĕbot kamoe sakti, njĕ sangkan djęmě 'ini bidapan, apě ragam diwě...., „mintaq sir di 'awaqkoe".

2) Het opsporen van ziekte door middel van "sir" en van "tēnong” noemt men „(mě)'ntjakagr toedjoe(w)'ăn". 


\section{BIJLAGE.}

Een andere "'oesoran těnong» luidt:

"sěram maqlajkom sěram, těkale Toe(w)'ăn měndikěnjěallah, "tělah gra'ib, běkatě 'ograng (๕)'mpat, kěsě Bidjębera'il (Gabriel) "kědoe(w)'と Měka'il (Michael), ketige Serrapil (Raphael) kěmpat «Djěra'il (?), maně katě Toe(w)'ăn, kaloe 'oemat 'allah těkědan «boentoe, moenggahlah kęgoenong bikoe tanjěka(n) 'anaq'adam, "sělellame mangkě timpoh 'oemat 'allah tetanggong pade bale «'idapan (ऍ)'ndiq ketoedohan, mangke Bidje bera'il menjoeroh"lah 'ograng doe(w)'と Se Patih djoengkar, doe(w)'e Patih djabaq "moenggah kěgoenong bikoe, Patih djoengkar na'iq k'atasnje, "sampaj di pinggang goenong bikoe betěmoelah pandite s'ograng "běsoenting sělasih 'itam sětangkaj bětoedong da'on kěmboelaw "sělambagr noekopi padi sěkoelak, mangkě běkatě panditě s'ograng "padě Patih djoengkar: toe(w)'ape kěrdje moenggah di goenong "bikoe, katě Patih djoengkar: (飞)'ndaq nanjěka(n) pætanje'an 'anaq "'adam sělělamě, mangkě kate panditě s'ograng: (ऍ)'ndaqlah "moenggah k'atas goenong bikoe djadilah, (๕)'nggan 'ini njelah "'akoe toedohi, 'inilah pětanje’an 'anaq 'adam sělelame bolih 'akoe "toendjoqka(n), ǩš bale 'idapan (๕)ndiq kětoedohan, kedoe(w)e "bada(h) běsoesok, kětigě kabagr dja'oh 'ataw mimpi, kěmpat "perr'oentongan gadis ngan boedjang, sěkali(j)'ăn 'itoe bolih ditan«jæka(n) dalam tenong, mangkě těnong 'ade (๕)'mpat, dalam "(̌)'mpat lagi sětěnong njělah těnong běasi njělah těnong padi, "mangkělarangan těnong padi adě (๕)'mpat, kěsě těnong boelaq, «kědoe(w)e těnong bandjolan, kětige těnong 'oejaw 'oejaw, kěmpat "těnong (飞)'ndiq bětoedoh, mangkě larangannje těnong nje (飞)'mpat "'itoe di mintaqka(n) Patih djoengkar kěpade panditě s'ograng "dan mintaq ditoelaqka(n), maněnje di mintaq njęlah těnong "sěsoenggohnje, 'oede itoe Patih djoengkar baliq toegron (me)'nda"pati Patih djabaq di bawah goenong bikoe, laloe kěmbali kěba"dahnje, njělah moelěnje mangkě 'ograng tahoe bettenong, sěram!', waarin verteld wordt, dat toen het menschdom in nood zat Gabriel aan Patih djoengkar bevel gaf om den berg "bikoe» te bestijgen, teneinde de ''anaq 'adam» om raad te vragen; hoe 
402 Kennis van HeT Shananisme bij DE PASémalers.

Patih djoengkar aan deze last gevolg gevende, op den bergrug een godgeleerde ontmoette, die hem de geheimen van de "trenong" openbaarde. Deze "'oesaran těnong, is kennelijk van een lateren datum, dan die, welke in den noot op bladz. 396 is opgenomen; men lette slechts op de uitheemsche bestanddeelen, zooals de namen der aartsengelen Gabriel, Raphael en Michael, woorden als «'oemat 'allah», «'anaq 'adam», enz. 